\title{
Effects of miR-129-3p on biological functions of prostate cancer cells through targeted regulation of Smad3
}

\author{
YUNPENG JIA $^{1 *}$, YU GAO ${ }^{2 *}$ and JIANGUO DOU ${ }^{2}$ \\ ${ }^{1}$ Department of Urology Surgery, Gansu Provincial Hospital of TCM, Lanzhou, Gansu 730050; \\ ${ }^{2}$ Department of Urology Surgery, The Dazu District People's Hospital, Chongqing 402360, P.R. China
}

Received September 6, 2019; Accepted November 5, 2019

DOI: 10.3892/ol.2019.11216

\begin{abstract}
Effects of miR-129-3p on the biological functions of prostate cancer cells through the targeted regulation of Smad3 were investigated. RT-PCR was used to detect the expression levels of miR-129-3p in prostate cancer tissues and cells and its target gene Smad3 mRNA determined by bioinformatics prediction. Correlation between miR-129-3p and Smad3 was analyzed. MTT assay, cell invasion detection, and apoptosis detection were conducted to detect the effects of miR-129-3p and Smad3 on the proliferation, invasion, and apoptosis of prostate cancer cells. The results of RT-qPCR showed that the expression level of miR-129-3p decreased but that of Smad3 increased in the prostate cancer tissue, and the expression levels of the two were significantly and negatively correlated. Additionally, the expression levels were closely related to the degree of tumor differentiation, TNM staging, and lymph node metastasis $(\mathrm{P}<0.05)$. Bioinformatics prediction and subsequent experiments proved that $\mathrm{Smad} 3$ was the direct target gene of miR-129-3p. Cell detection confirmed that the overexpression of miR-129-3p or the inhibition of Smad3 expression inhibited the proliferation and invasion of prostate cancer cells, promoting apoptosis, and increased the expression level of pro-apoptotic protein Bax, as well as decreased the expression level of anti-apoptotic protein Bcl-2. Inhibition of miR-129-3p expression had the opposite effect to overexpression. miR-129-3p, which may be a new and potential target for the treatment of prostate cancer, can inhibit the proliferation and invasion of prostate cancer cells and promote their apoptosis by directly targeting Smad3.
\end{abstract}

Correspondence to: Dr Jianguo Dou, Department of Urology Surgery, The Dazu District People's Hospital, 1073 Rrhuan South Road, Chongqing 402360, P.R. China

E-mail: dxy7gy@163.com; hustdjg@163.com

${ }^{*}$ Contributed equally

Key words: miR-129-3p, Smad3, prostate cancer cells, biological functions

\section{Introduction}

Prostate cancer is a common malignant tumor of the male reproductive system. Its incidence has been rising with the changes of social environment in recent years, and its mortality rate ranks high among tumors of the urinary system $(1,2)$. The disease is difficult to be diagnosed in its early stage due to the lack of effective diagnostic methods, so it has usually progressed to the advanced stage when confirmed. Accordingly, many patients with the disease cannot be operated for radical cure, which seriously endangers their life and health (3). With the development of molecular biology, the role of microRNA (miRNA) in tumors has been increasingly valued, which also provides a new direction for the diagnosis and treatment of prostate cancer.

As a non-coding single-stranded RNA, miRNA affects the biological functions of cells through its complete or incomplete complementary binding to the 3 '-end of target genes $(4,5)$. miR-129 is a miRNA located in the genomic region near the fragile site of chromosome 7q (6), and fragile site loss is closely related to the malignancy of prostate cancer (7). miR-129-3p is a miRNA closely correlated with the development and progression of tumors and the expression is low in gastric cancer (8) and breast cancer (9), functioning as a tumor suppressor gene. Smad3 is a transporter that plays a pivotal role in transforming growth factor- $\beta$ (TGF- $\beta$ ) signaling pathway, and it can promote the invasion and metastasis of tumor cells (10). In this study, a bioinformatics website (TargetScan) predicted that Smad3 may be a target gene of miR-129-3p.

In this study, the effects of miR-129-3p on the biological functions of prostate cancer cells as well as its potential targeted and regulatory mechanism were explored, so as to provide more experimental data for the mechanism research of prostate cancer.

\section{Materials and methods}

Experimental reagents and materials. A total of 74 patients who were pathologically diagnosed with prostate cancer and then underwent radical prostatectomy in Gansu Provincial Hospital of TCM (Lanzhou, China) from 2015 to 2018 were enrolled. All of them had stages I-III of prostate cancer. Detailed information is shown in Table I. After receiving consent, their prostate cancer and adjacent tissues ( $\mathrm{n}=74$ each) were obtained 
during the operation and stored in a liquid nitrogen container. Prostate cancer cells (PC-3, DU-145, and LNCaP cells) and human prostate epithelial cell RWPE-1 (Shanghai Institute of Cell Biology); fetal bovine serum (FBS) and trypsin (Gibco; Thermo Fisher Scientific, Inc.); phosphate buffer solution (PBS) (Hyclone; GE Healthcare Life Sciences); dimethyl sulfoxide (DMSO) (Sigma-Aldrich; Merck KGaA); TRIzol reagent (Invitrogen; Thermo Fisher Scientific, Inc.); dual luciferase reporter gene assay detection kit (Solarbio); reverse transcription kit and PCR master mix (Fermentas; Thermo Fisher Scientific, Inc.); RIPA and BCA protein kit (Thermo Fisher Scientific, Inc.); Annexin V-FITC/PI apoptosis kit (Jiangsu KeyGEN Bio TECH Corp., Ltd.); Transwell chamber (Corning, Inc.); Matrigel (Beijing BioDee Biotechnology Co., Ltd.); Smad3, Bax, Bcl-2 and $\beta$-actin antibodies (Cell Signaling Technology); goat anti-rabbit IgG secondary antibody (Wuhan Boster Biological Technology Co., Ltd.); ECL developer (Thermo Fisher Scientific, Inc.). Primers for miR-129-3p and miR-NC were designed and synthesized by Sangon Biotech Shanghai Co., Ltd.

The study was approved by the Ethics Committee of Gansu Provincial Hospital of TCM (Lanzhou, China).

RT-PCR detection of miR-129-3p and Smad3 expression levels. The prostate cancer tissue and the adjacent tissue were taken from the liquid nitrogen container for grinding. PC-3, DU-145, LNCaP and RWPE-1 cells were prepared into a cell suspension. The TRIzol reagent was used to extract total RNA from the tissues and cells, and an ultraviolet spectrophotometer was used to detect its purity and concentration. Each $5 \mu \mathrm{g}$ of the total RNA was reverse transcribed into cDNA according to the instructions of the kits. The parameters were as follows: at $37^{\circ} \mathrm{C}$ for $15 \mathrm{~min}$, at $42^{\circ} \mathrm{C}$ for $42 \mathrm{~min}$, and at $70^{\circ} \mathrm{C}$ for $5 \mathrm{~min}$. The transcribed cDNA was used for PCR amplification, during which $\beta$-actin was considered as an internal reference for Smad3 mRNA and U6 was considered as an internal reference for miR-129-3p. The reaction system was as follows: $1 \mu 1$ of cDNA, each $0.2 \mu \mathrm{l}$ of upstream and downstream primers, $10 \mu \mathrm{l}$ of 2X Real-time PCR Master mix, $0.4 \mu \mathrm{l}$ of Passive Reference Dye (50X), and $\mathrm{ddH}_{2} \mathrm{O}$ up to $20 \mu \mathrm{l}$. The conditions for $\mathrm{Smad} 3$ mRNA were as follows: pre-denaturation at $95^{\circ} \mathrm{C}$ for $5 \mathrm{~min}$, and then cycling at $95^{\circ} \mathrm{C}$ for $30 \mathrm{sec}$ and at $60^{\circ} \mathrm{C}$ for $45 \mathrm{sec}$ for 40 times. The conditions for miR-129-3p were: pre-denaturation at $95^{\circ} \mathrm{C}$ for $15 \mathrm{~min}$, cycling at $94^{\circ} \mathrm{C}$ for $10 \mathrm{sec}$ and at $55^{\circ} \mathrm{C}$ for $40 \mathrm{sec}, 40$ times, and finally extension at $72^{\circ} \mathrm{C}$ for $30 \mathrm{sec}$. The upstream and downstream primers for miR-129-3p were 5'-CTTGTTGCGGTCTGG-3' and 5'-TGCAGGGTCCGA GGT-3'. The primers for U6 were 5'-CTCGTCTCGGCAGC ACA-3' and 5'-AACGCTTCACGAATTTGCGT-3'. The primers for Smad3 mRNA were 5'-GGAACTTACAAGGCGA CAC-3' and 5'-TGGGAGACTGGACGAAA-3'. The primers for $\beta$-actin were 5'-CCCATCTA CGAGGGCTAT-3' and 5'-TGTCACGCACGATTTCC-3'. The relative expression of genes was expressed by $2^{-\Delta \Delta C T}$. A PCR instrument was used for real-time fluorescence quantitative PCR. The experiment was carried out 3 times. Calculation methods were as follows: for all test samples and calibration samples, the CT value of the internal reference gene was used to normalize that of the target gene: $\Delta \mathrm{CT}$ (test) $=\mathrm{CT}$ (target, test) - CT (ref, test) $\Delta \mathrm{CT}$ (calibrator $)=\mathrm{CT}$ (target, calibrator) $-\mathrm{CT}$ (ref, calibrator). Next, the
$\Delta \mathrm{CT}$ value of the calibration samples was used to normalize that of the test samples: $\Delta \Delta \mathrm{CT}=\Delta \mathrm{CT}$ (test) $-\Delta \mathrm{CT}$ (calibrator). Finally, the ratio of expression level was calculated: $2-\Delta \Delta \mathrm{CT}=$ the ratio of expression.

Cell culture, passage, and transfection. The detection of miR-129-3p and Smad3 RNA expression levels showed that the expression level of miR-129-3p in PC-3 and LNCaP cells was lower than that in DU-145 cells, so PC-3 and LNCaP cells were selected for transfection and subsequent experiments. The two kinds of cells were cultured in a DMEM containing $10 \%$ PBS at $37^{\circ} \mathrm{C}$ and with $5 \% \mathrm{CO}_{2}$. When the adherent growth and fusion reached $85 \%$, the cells were digested with $25 \%$ trypsin and then continuously cultured in the medium for passage. Cas9 backbone plasmid was digested with two restriction endonucleases (KpnI and XhoI), and then the digested product was recovered through agarose gel electrophoresis. The digested fragment was about $5 \mathrm{~kb}$. After that, miR-129-3p-mimics, miR-129-3p-inhibitor, miR-NC, Si-Smad3, and Si-NC were, respectively, transfected into cells in the logarithmic phase. According to the instruction of the Lipofectamine 2000 manufacturer's kit, Lipofectamine 2000 was mixed with miR-129-3p-mimics and then incubated at room temperature for $5 \mathrm{~min}$. Finally, the mixture was evenly mixed with the cells and then transfected at $37^{\circ} \mathrm{C}$ with $5 \% \mathrm{CO}_{2}$.

MTT assay for cell proliferation. The cells transfected for $48 \mathrm{~h}$ were inoculated into a 96-well plate, $\sim 100 \mu \mathrm{l} /$ well and $2 \times 10^{3}$ cells $/ \mathrm{ml}$, and then incubated at $37^{\circ} \mathrm{C}$. At the first, third, and fifth days of the incubation, the cells in each well were added with $20 \mu \mathrm{l}$ of MTT solution respectively, and then continuously cultured in an incubator for $4 \mathrm{~h}$. Then, they were added with $150 \mu \mathrm{l}$ of DMSO and shaken for $10 \mathrm{~min}$. Finally, a microplate reader was used to measure the optical density (OD) values at $490 \mathrm{~nm}$, so as to detect cell proliferation. The experiment was carried out 3 times.

Transwell chamber assay for cell invasion in vitro. Matrigel was placed at $4^{\circ} \mathrm{C}$ overnight, and then the liquefied Matrigel was diluted at 1:8. The transfected PC-3 cells were starved for $24 \mathrm{~h}$ and then resuspended with FBS-free DMEM culture solution. After the cell density was adjusted to $2 \times 10^{5}$ cells $/ \mathrm{ml}$, the cells were inoculated in the Transwell chambers of a 24-well plate. After each chamber was added with about $200 \mu \mathrm{l}$ of the cell suspension, the lower chamber in the plate was added with $600 \mu \mathrm{l}$ of DMEM culture solution containing 10\% FBS, and then the cells were cultured for $24 \mathrm{~h}$ in an incubator at $37^{\circ} \mathrm{C}$. The supernatant was removed with cotton swabs and the chamber was washed with PBS. The cells in the lower chamber were fixed with $95 \%$ ethanol solution for $30 \mathrm{~min}$, and then the chamber was washed again with PBS. Each well was added with about $600 \mu \mathrm{l}$ of $0.1 \%$ crystal violet for staining. The number of migrated cells in 5 random wells was calculated with a microscope, to calculate the average value. The experiment was carried out 3 times.

Apoptosis. Annexin V-FITC/PI double staining combined with flow cytometry was used to detect apoptosis. The transfected cells were inoculated in a 6 -well plate at $3 \times 10^{5}$ cells/well, digested with $0.25 \%$ trypsin, and then washed twice with 
Table I. General information.

\begin{tabular}{lc}
\hline Information & $\begin{array}{r}\text { Patients with prostate } \\
\text { cancer }(\mathrm{n}=74)\end{array}$ \\
\hline Age (years) & $58.34 \pm 8.46$ \\
BMI $\left(\mathrm{kg} / \mathrm{m}^{2}\right)$ & $22.89 \pm 1.22$ \\
Pathological types & \\
Adenocarcinoma & $25(33.78)$ \\
Squamous cell carcinoma & $27(36.49)$ \\
Adenosquamous carcinoma & $22(29.73)$ \\
Pathological stages & \\
Stage I & $21(30.43)$ \\
Stage II & $26(37.68)$ \\
Stage III & $22(31.88)$ \\
Degree of differentiation & \\
High & $20(28.99)$ \\
Moderate & $23(33.33)$ \\
Low & $26(37.68)$ \\
\hline
\end{tabular}

PBS. The cells were added with $100 \mu \mathrm{l}$ of binding buffer to prepare into a cell suspension at $1 \times 10^{6}$ cells $/ \mathrm{ml}$. The cells were sequentially added with Annexin V-FITC and PI, and then incubated at room temperature in the dark for $5 \mathrm{~min}$. Finally, a flow cytometer was used to detect apoptosis and calculate the average value. The experiment was carried out 3 times.

Western blotting. RIPA lysis method was used to extract the total protein from the collected cells, and BCA protein assay was used to detect its concentration. The protein was separated by electrophoresis with $12 \%$ SDS-PAGE, transferred to PVDF membrane, and then sealed with $5 \%$ skimmed milk powder at room temperature for $2 \mathrm{~h}$. After that, the membrane was added with mouse monoclonal antibodies [Smad3 (1:500), Bax (1:500), Bcl-2 (1:500), and $\beta$-actin $(1: 1,000)]$, and sealed overnight at $4^{\circ} \mathrm{C}$. After washing to remove the primary antibodies, the membrane was added with goat anti-rabbit $(1: 3,000)$, incubated at $37^{\circ} \mathrm{C}$ for $1 \mathrm{~h}$, and rinsed with PBS 3 times. Finally, the excess liquid was absorbed dry, and the protein was luminesced and developed with ECL.

Dual luciferase reporter gene assay. Dual luciferase reporter gene assay was performed to determine whether Smad3 was the direct target gene of miR-129-3p. Smad3 3'UTR dual luciferase reporter plasmids (WT and MUT) that were chemically synthetized by $X b a \mathrm{I} / X b a \mathrm{I}$ digestion were, respectively, co-transfected into PC-3 cells with miR-129-3p-mimics or miR-NC using Lipofectamine 2000. After 48-h incubation, the luciferase activity was detected by the dual luciferase reporter system.

Statistical methods. SPSS 19.0 was used for statistical analysis. GraphPad Prism 6 was used to plot figures. Measurement data were expressed as mean \pm standard deviation (means \pm SD) and analyzed by t-test. Comparison between groups was analyzed by independent samples t-test and represented by t-test. Comparison between multiple groups was analyzed by one-way analysis of variance, and post hoc pairwise comparison was analyzed by LSD t-test. Pearson was used for correlation analysis. $\mathrm{P}<0.05$ was considered to indicate a statistically significant difference.

\section{Results}

Expression levels of miR-129-3P and Smad3 and their correlation. The expression levels of miR-129-3p and Smad3 mRNA in prostate cancer and adjacent tissues were detected by qRT-PCR. Compared with those in the adjacent tissue, the expression level of miR-129-3p in the prostate cancer tissue significantly decreased $(\mathrm{P}<0.05)$, while the expression level of Smad3 significantly increased $(\mathrm{P}<0.05)$. The expression levels of miR-129-3p and Smad3 protein in PC-3, DU-145, LNCaP, and RWPE-1 cells were detected. The expression level of miR-129-3p in PC-3, DU-145, and LNCaP cells was lower than that in RWPE-1 cells $(\mathrm{P}<0.05)$, while the expression level of Smad3 was higher than that in RWPE-1 cells $(\mathrm{P}<0.05)$. The expression levels of miR-129-3p and Smad3 protein were negatively correlated $(r=-0.855, P<0.001)$. According to the analysis of the correlations of miR-129-3p and Smad3 with the clinicopathological features, the expression levels of miR-129-3p and Smad3 were closely related to the degree of tumor differentiation, TNM staging, and lymph node metastasis $(\mathrm{P}<0.05)$ (Table II and Fig. 1).

Effects of miR-129-3p on biological functions of prostate cancer cells. PC-3 and LNCaP cells were transfected with miR-129-3p mimics, miR-129-3p inhibitor, or miR-NC for $48 \mathrm{~h}$, to explore the effects of miR-129-3p overexpression on the proliferation, invasion, and apoptosis of prostate cancer cells. Compared with those transfected with miR-NC, the expression level of miR-129-3p in the PC-3 and LNCaP cells transfected with miR-129-3p-mimics significantly increased, while the expression level in those transfected with miR-129-3p-inhibitor significantly decreased (Fig. $2 \mathrm{~A}$ and $\mathrm{B}, \mathrm{P}<0.05$ ). After transfection, MTT assay, cell invasion detection, and flow cytometry were conducted. The overexpression of miR-129-3p significantly inhibited the proliferation and invasion of the cells and promoted apoptosis (Fig. 2C-E, $\mathrm{P}<0.05$ ). According to the results of western blotting, the overexpression increased the expression level of pro-apoptotic protein Bax while decreased the expression level of anti-apoptotic protein Bcl-2. However, the inhibition of miR-129-3p expression significantly promoted the proliferation and invasion of the cells, inhibited apoptosis, and decreased the expression level of pro-apoptotic protein Bax, as well as increased the expression level of anti-apoptotic protein Bcl-2 (Fig. 2).

Effects of Smad3 on biological functions of prostate cancer cells. PC-3 and LNCaP cells were transfected with Si-Smad3 or $\mathrm{Si}-\mathrm{NC}$ for $48 \mathrm{~h}$, to explore the effects of Smad3 on the proliferation, invasion and apoptosis of prostate cancer cells. Compared with those transfected with $\mathrm{Si}-\mathrm{NC}$, the expression level of Smad3 in the PC-3 and LNCaP cells transfected with $\mathrm{Si}-\mathrm{Smad} 3$ significantly decreased $(\mathrm{P}<0.05)$. After transfection, MTT assay, cell invasion detection, and flow cytometry were conducted. The proliferation and invasion of the cells transfected with Si-Smad3 were significantly inhibited while the 
Table II. Correlation of miR-129-3p and Smad3 with clinicopathological features.

\begin{tabular}{|c|c|c|c|c|c|c|}
\hline Factors & $\begin{array}{l}\text { Relative expression } \\
\text { of miR-129-3p }\end{array}$ & t/F-value & P-value & $\begin{array}{c}\text { Relative expression } \\
\text { of } \mathrm{Smad} 3\end{array}$ & $\mathrm{t} / \mathrm{F}$-value & P-value \\
\hline Age & & 0.953 & 0.344 & & 0.391 & 0.697 \\
\hline$<58$ years $(\mathrm{n}=36)$ & $0.51 \pm 0.05$ & & & $2.12 \pm 0.34$ & & \\
\hline$\geq 58$ years $(n=38)$ & $0.52 \pm 0.04$ & & & $2.15 \pm 0.32$ & & \\
\hline TNM staging & & 17.43 & $<0.001$ & & 15.93 & $<0.001$ \\
\hline I and II $(n=47)$ & $0.69 \pm 0.07$ & & & $1.69 \pm 0.21$ & & \\
\hline III $(n=22)$ & $0.41 \pm 0.04$ & & & $2.95 \pm 0.45$ & & \\
\hline Pathological types & & 0.838 & 0.437 & & 0.292 & 0.747 \\
\hline Adenocarcinoma $(n=25)$ & $0.46 \pm 0.05$ & & & $2.09 \pm 0.32$ & & \\
\hline Squamous cell carcinoma $(n=27)$ & $0.47 \pm 0.06$ & & & $2.16 \pm 0.34$ & & \\
\hline Adenosquamous carcinoma $(n=22)$ & $0.45 \pm 0.05$ & & & $2.13 \pm 0.33$ & & \\
\hline Lymph node metastasis & & 18.63 & $<0.001$ & & 13.46 & $<0.001$ \\
\hline Yes $(n=29)$ & $0.40 \pm 0.05$ & & & $3.02 \pm 0.48$ & & \\
\hline No $(n=45)$ & $0.71 \pm 0.08$ & & & $1.72 \pm 0.35$ & & \\
\hline Degree of differentiation & & 14.95 & $<0.001$ & & 10.26 & $<0.001$ \\
\hline Low $(n=20)$ & $0.40 \pm 0.04$ & & & $2.86 \pm 0.62$ & & \\
\hline Moderate and high $(n=49)$ & $0.62 \pm 0.06$ & & & $1.68 \pm 0.31$ & & \\
\hline
\end{tabular}
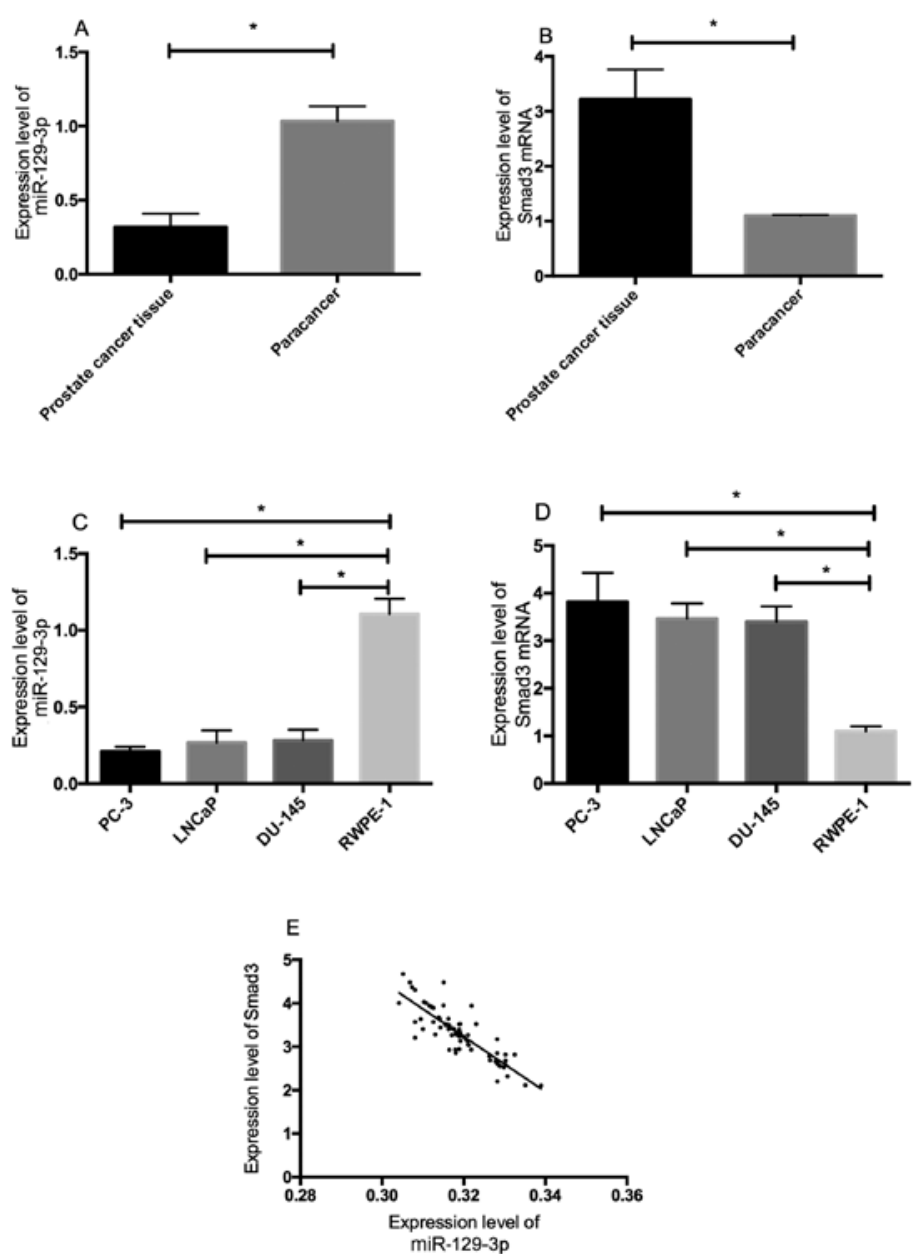

Figure 1. Correlation of the expression levels of miR-129-3p and Smad3. (A) Compared with that in the adjacent tissue, the expression level of miR-129-3p in the prostate cancer tissue significantly decreased. (B) Compared with that in the adjacent tissue, the expression level of Smad3 in the prostate cancer tissue significantly increased. (C) The expression level of miR-129-3p in PC-3, DU-145 and LNCaP cells was lower than that in RWPE-1 cells. (D) The expression level of Smad3 in PC-3, DU-145 and LNCaP cells was higher than that in RWPE-1 cells. (E) The expression levels of miR-129-3p and Smad3 were negatively correlated $(r=-0.855, \mathrm{P}<0.001)$. ${ }^{*} \mathrm{P}<0.05$. 
A

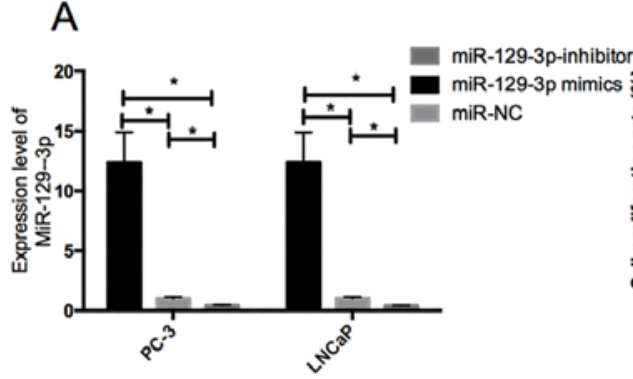

C
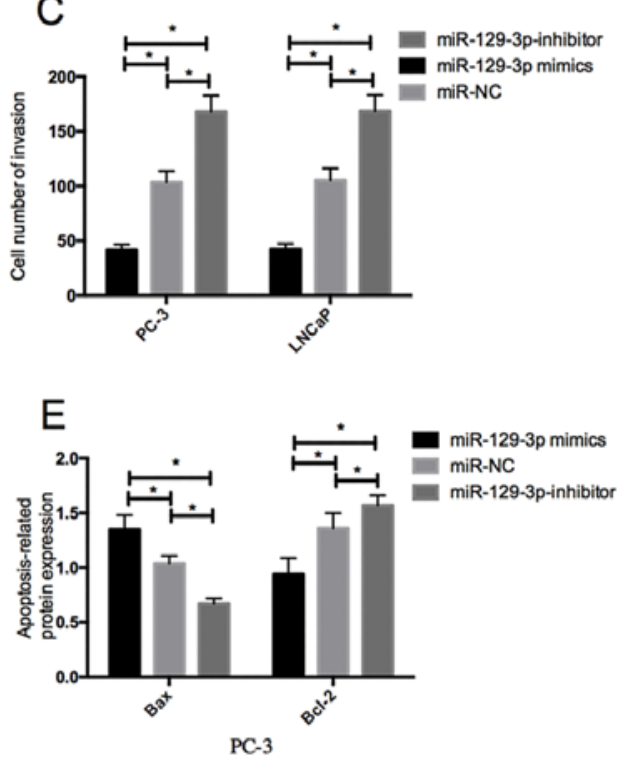

B
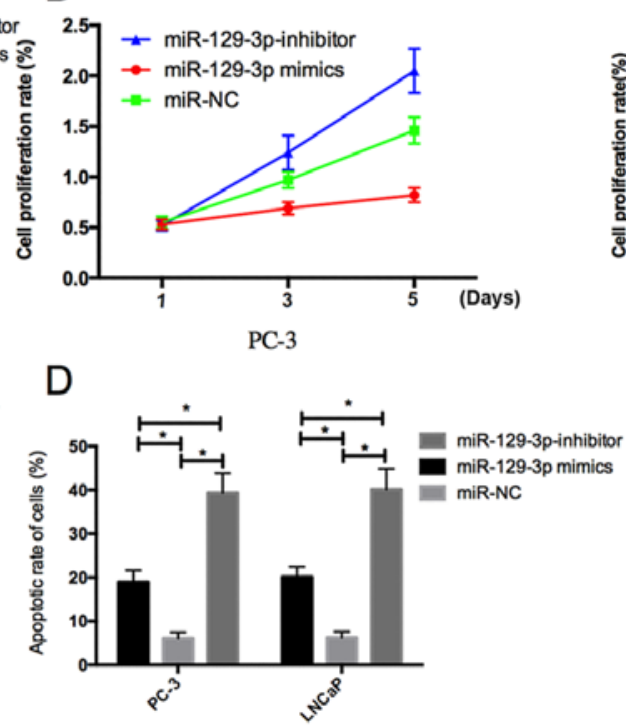
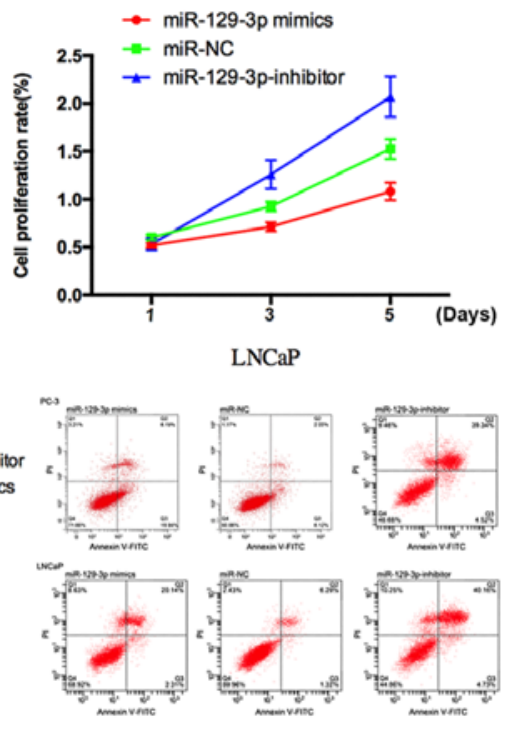
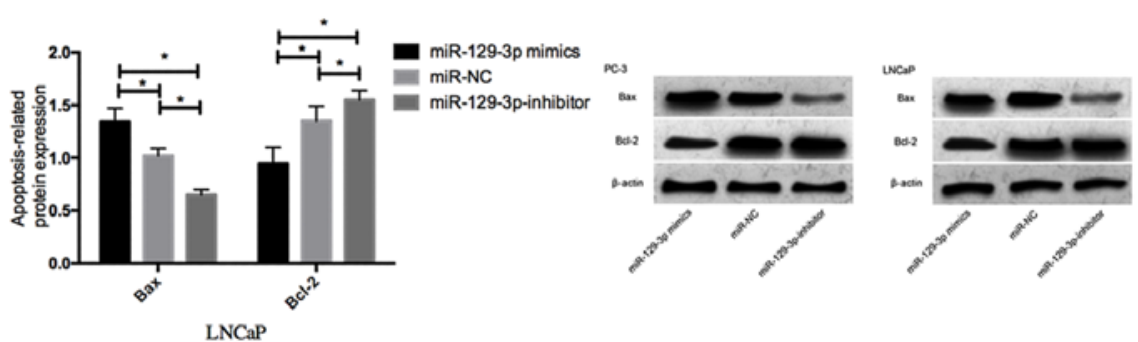

Figure 2. Effects of miR-129-3p on the biological functions of prostate cancer cells. (A) The expression level of miR-129-3p in prostate cancer cells after transfection significantly increased. (B) Upregulation of miR-129-3p expression inhibits the proliferation of prostate cancer cells. (C) Upregulation of miR-129-3p expression inhibits the invasion of prostate cancer cells. (D) Upregulation of miR-129-3p expression promotes apoptosis of prostate cancer cells. (E) Upregulation of miR-129-3p expression increases the expression of Bax but decreases the expression level of $\mathrm{Bcl}-2$. * $\mathrm{P}<0.05$.

apoptotic rate significantly increased. According to the results of western blotting, the expression level of pro-apoptotic protein Bax in the cells transfected with $\mathrm{Si}-\mathrm{Smad} 3$ increased, while the expression level of anti-apoptotic protein Bcl-2 decreased (Fig. 3).

Smad3 as the direct target gene of $m i R-129-3 p$. Bioinformatics analysis was conducted to predict the target gene of miR-129-3p, to explore the potential mechanism of miR-129-3p in prostate cancer. Smad3 was identified as the target gene of miR-129-3p. Dual luciferase reporter gene assay was carried out to determine whether Smad3 3'UTR could be directly targeted by miR-129-3p. The overexpression of miR-129-3p decreased the luciferase activity of position 1,205-1,212 of Smad3 3'UTR Wt $(\mathrm{P}<0.05)$, without effect on position $1,205-1,212$ of Smad3 3'UTR Mut. According to the results of western blotting, the expression level of Smad3 protein in PC-3 cells transfected with miR-129-3p-mimics decreased $(\mathrm{P}<0.05)$ (Fig. 4).

\section{Discussion}

miRNA is a non-coding RNA closely related to the development and progression of tumors, and its role in prostate cancer has been widely discussed in recent years (11). There are various miRNA targets that can be used for the diagnosis and treatment of prostate cancer, with more tumor suppressor genes and fewer oncogenes $(12,13)$. A study has shown that the upregulation of miR-101 inhibits the proliferation and invasion of prostate cancer cell line DU145 by inhibiting its target gene EZH2 (14). miR-129 is a newly discovered miRNA that is closely associated with the pathogenesis of prostate cancer. According to previous studies, it regulates the growth hormone receptor (GHR) of target genes in LNCaP cells, thereby inhibiting the proliferation of prostate cancer cells (15). It also controls the centrosome number of metastatic prostate cancer cells by inhibiting CP110, thus affecting prostate cancer (16).

In this study, bioinformatics prediction showed that Smad3 was the direct target gene of miR-129-3p. A previous study reported that Smad3 promotes epithelial-mesenchymal transition of prostate cancer cells and functions as an oncogene in the cells (17). Therefore, we speculated that miR-129-3p could play a role in prostate cancer cells by regulating Smad3. According to the results of qRT-PCR, the expression level of miR-129-3p in the prostate cancer tissue and in PC-3, DU-145, and LNCaP cells significantly increased, while that of Smad3 mRNA significantly decreased. In the present study, bioinformatics prediction showed the target relationship between miR-129-3p and Smad3. According to the results of the dual luciferase reporter gene assay, the 
A

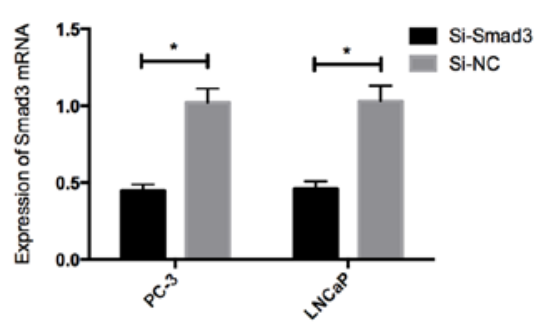

C

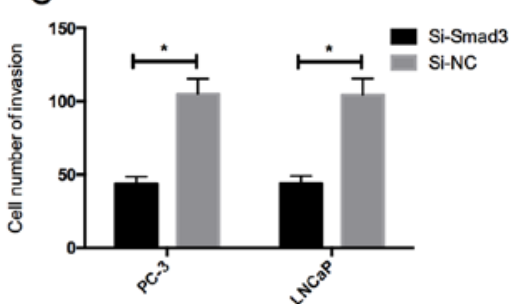

E

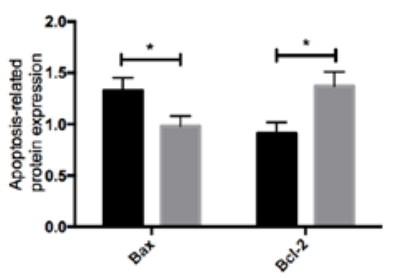

B

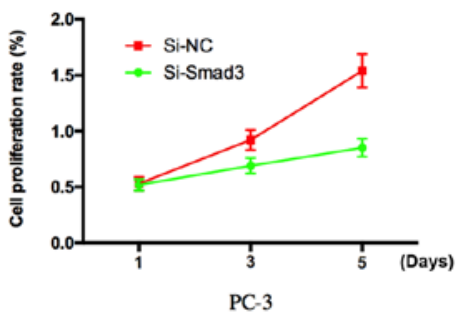

D
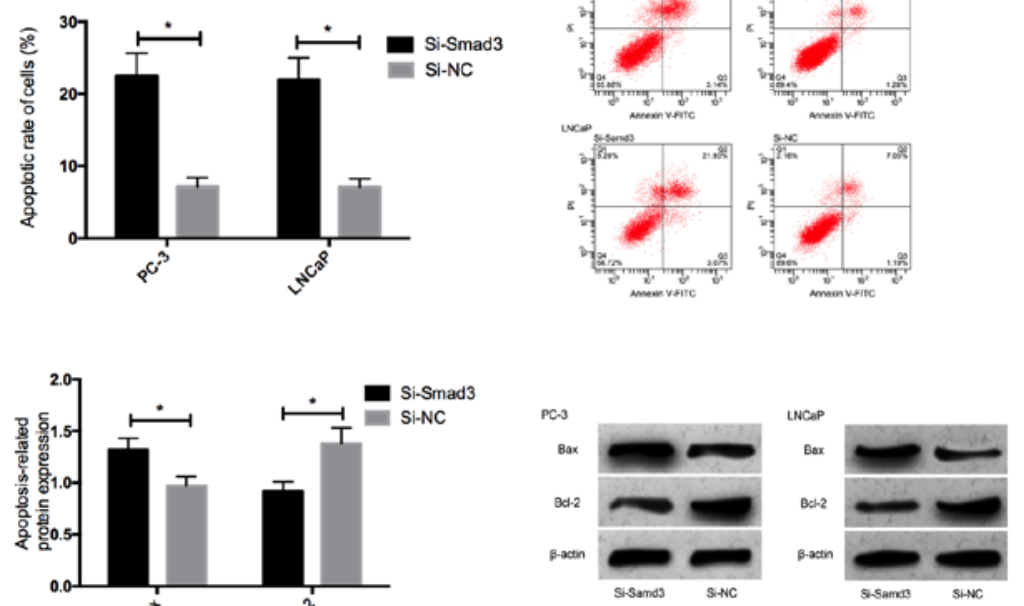
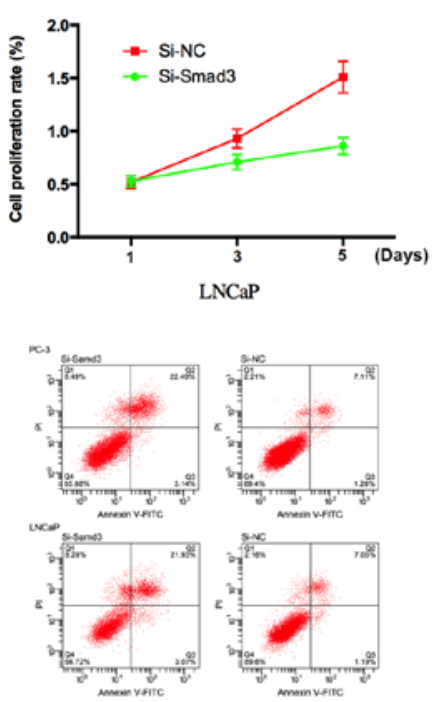

Sisames SiNC

PC-3
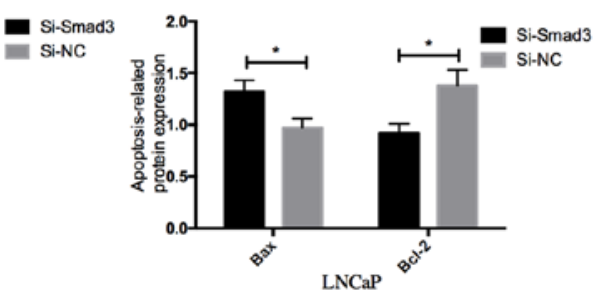

Figure 3. Effects of Smad3 on biological functions of prostate cancer cells. (A) The expression level of Smad3 in prostate cancer cells after transfection significantly decreased. (B) The downregulation of Smad3 expression inhibits the proliferation of prostate cancer cells. (C) Downregulation of Smad3 expression inhibits the invasion of prostate cancer cells. (D) Downregulation of Smad3 expression promoted apoptosis of prostate cancer cells. (E) Downregulation of Smad3 expression increases the expression level of Bax but decrease the expression level of Bcl-2. ${ }^{*} \mathrm{P}<0.05$.

A

\begin{tabular}{|c|c|c|c|}
\hline $\begin{array}{l}\text { Position } 1205-1212 \text { of SMAD3 } 3^{\prime} \text { UTR } 5^{\prime} \\
\text { hsa-miP-129-2-3p }\end{array}$ & $\begin{array}{l}\text {... ACAUAGGCAAAUGAAAAGGGCUA... } \\
\text { IIIIIII } \\
\text {.ACGAAAACCCCAIICCCGAA }\end{array}$ & 8mer & -0.48 \\
\hline
\end{tabular}

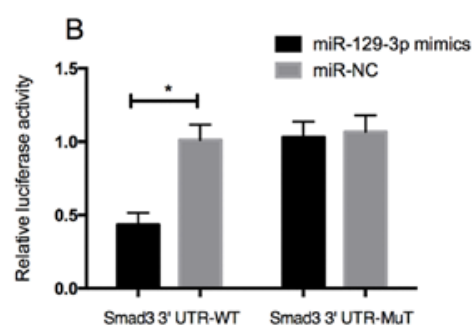

D

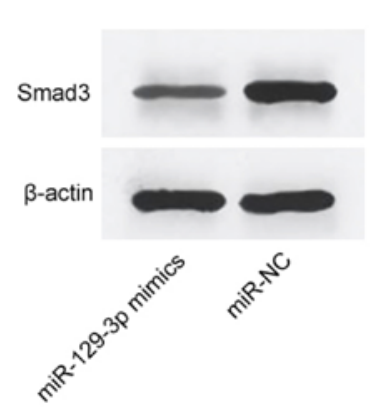

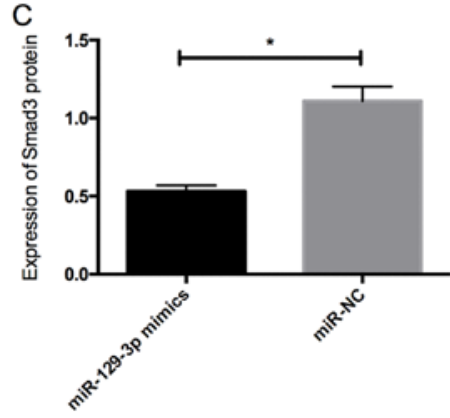

Figure 4. Smad3 as the direct target gene of miR-129-3p. (A) Sequence alignment of putative binding sites in miR-129-3p and Smad3 wild-type regions. (B) miR-129-3p-mimics decreased the fluorescence intensity of PC-3 cells transfected with Smad3-Wt, without effect on Smad3-Mut vectors. (C) Expression level of Smad3 protein in PC-3 cells transfected with miR-129-3p-mimics decreased. (D) Western blot. ${ }^{*} \mathrm{P}<0.05$. 
overexpression of miR-129-3p reduced the luciferase activity of position 1,205-1,212 of Smad3 3'UTR Wt, without effect on position 1,205-1,212 of Smad3 3'UTR Mut. This suggests that Smad3 may be a direct target gene of miR-129-3p. As a multifunctional cytokine, transforming growth factor- $\beta$ (TGF- $\beta$ ) plays a certain role in cells in autocrine and paracrine manner. Smad3 is an important member of the Smad protein family and a major component of TGF- $\beta / \mathrm{Smad}$ signaling pathway $(18,19)$. We regulated the expression level of Smad3 and found that the downregulation of the expression level significantly inhibited the proliferation and invasion of prostate cancer cells, but significantly increased the apoptotic rate of the cells. A study has shown that the high expression of Smad3 is closely correlated with the recurrence and prognosis of prostate cancer (20). At diagnosis, prostate cancer has mostly progressed into castration-resistant prostate cancer (21), in which Smad3 promotes the expression of prostate specific antigens and finally the growth of prostate cancer cells through the auxiliary activation of androgen receptors $(22,23)$. These studies support our conclusions.

In order to further confirm the effects of miR-129-3p on the biological functions of prostate cancer cells, miR-129-3p in PC-3 cells was overexpressed through plasmid transfection. The expression level of Smad 3 and the proliferation, invasion, and apoptosis of PC-3 cells after the overexpression were also detected. The results showed that the overexpression of miR-129-3p significantly inhibited the proliferation and invasion of PC-3 cells, promoted apoptosis, and significantly decreased the expression level of Smad3 protein. These findings indicate that miR-129-3p may function as a tumor suppressor gene by inhibiting the expression level of Smad3 protein. Apoptosis detection showed that the overexpression of miR-129-3p increased the expression level of pro-apoptotic protein Bax but decreased the expression level of anti-apoptotic protein Bcl-2, which shows that the pro-apoptotic function of miR-129-3p may be related to the regulation of apoptosis-related proteins. Based on previous studies, miR-129-3p regulates the expression level of oncogene WWP1 and then inhibits the proliferation and metastasis of gastric cancer cells (24). It can also inhibit the growth of glioblastoma cells through the targeted regulation of E2F5 gene (25).

Based on our study miR-129-3p may affect the biological functions of prostate cancer cells through the targeted regulation of Smad3. However, it remains unclear how miR-129-3p regulates other related targets and whether these targets have a synergistic effect with Smad3, which needs further investigation.

In summary, miR-129-3p expression is low in prostate cancer tissue, and inhibits the proliferation and migration of the cells and induces apoptosis by negatively regulating the expression level of Smad3, so it may be a potential target for the diagnosis and treatment of prostate cancer.

\section{Acknowledgements}

Not applicable.

\section{Funding}

No funding was received.

\section{Availability of data and materials}

The datasets used and/or analyzed during the present study are available from the corresponding author on reasonable request.

\section{Authors' contributions}

YJ designed the study and wrote the manuscript. YG was responsible for all the experiments. JD helped with statistical analysis. All authors read and approved the final manuscript.

\section{Ethics approval and consent to participate}

The study was approved by the Ethics Committee of Gansu Provincial Hospital of TCM (Lanzhou, China). Patients who participated in this research had complete clinical data. Signed informed consents were obtained from the patients or the guardians.

\section{Patient consent for publication}

Not applicable.

\section{Competing interests}

The authors declare that they have no competing interests.

\section{References}

1. Fizazi K, Tran N, Fein L, Matsubara N, Rodriguez-Antolin A, Alekseev BY,Özgüroğlu M, YeD, Feyerabend S, Protheroe A, et al: Abiraterone plus Prednisone in metastatic, castration-sensitive prostate cancer. Lancet Oncol 20: 686-700, 2019.

2. Gillessen S, Attard G, Beer TM, Beltran H, Bossi A, Bristow R, Carver B, Castellano D, Chung BH, Clarke N, et al: Management of patients with advanced prostate cancer: The report of the Advanced Prostate Cancer Consensus Conference APCCC 2017. Eur Urol 73: 178-211, 2018.

3. Madaan S, Abel PD, Chaudhary KS, Hewitt R, Stott MA Stamp GW and Lalani EN: Cytoplasmic induction and over-expression of cyclooxygenase-2 in human prostate cancer: Implications for prevention and treatment. BJU Int 86: 736-741, 2000.

4. Hao NB, He YF,Li XQ, Wang K and Wang RL: The role of miRNA and lncRNA in gastric cancer. Oncotarget 8: 81572-81582, 2017.

5. Fang H, Xie J, Zhang M, Zhao Z, Wan Y and Yao Y: miRNA-21 promotes proliferation and invasion of triple-negative breast cancer cells through targeting PTEN. Am J Transl Res 9: 953-961, 2017.

6. Liu K, Huang J, Ni J, Song D, Ding M, Wang J, Huang X and Li W: MALAT1 promotes osteosarcoma development by regulation of HMGB1 via miR-142-3p and miR-129-5p. Cell Cycle 16: 578-587, 2017.

7. Lin VC, Huang SP, Ting HJ, Ma WL, Yu CC, Huang CY, Yin HL, Huang TY, Lee $\mathrm{CH}$, Chang TY, et al: Vitamin D receptor-binding site variants affect prostate cancer progression. Oncotarget 8: 74119-74128, 2017.

8. Lu C, Shan Z, Li C and Yang L: miR-129 regulates cisplatinresistance in human gastric cancer cells by targeting P-gp. Biomed Pharmacother 86: 450-456, 2017.

9. Zuo Y, Li Y, Zhou Z, Ma M and Fu K: Long non-coding RNA MALAT1 promotes proliferation and invasion via targeting miR-129-5p in triple-negative breast cancer. Biomed Pharmacother 95: 922-928, 2017.

10. Tang PM, Zhou S, Meng XM, Wang QM, Li CJ, Lian GY, Huang XR, Tang YJ, Guan XY, Yan BP, et al: Smad3 promotes cancer progression by inhibiting E4BP4-mediated NK cell development. Nat Commun 8: 14677, 2017. 
11. Pashaei E, Pashaei E, Ahmady M, Ozen M and Aydin N: Meta-analysis of miRNA expression profiles for prostate cancer recurrence following radical prostatectomy. PLoS One 12: e0179543, 2017.

12. Lu S, Wang MS, Chen PJ, Ren Q and Bai P: miRNA-186 inhibits prostate cancer cell proliferation and tumor growth by targeting YY1 and CDK6. Exp Ther Med 13: 3309-3314, 2017.

13. Liu C, Liu R, Zhang D, Deng Q, Liu B, Chao HP, Rycaj K, Takata Y, Lin K, Lu Y, et al: MicroRNA-141 suppresses prostate cancer stem cells and metastasis by targeting a cohort of pro-metastasis genes. Nat Commun 8: 14270, 2017.

14. Varambally S, Cao Q, Mani RS, Shankar S, Wang X, Ateeq B, Laxman B, Cao X, Jing X, Ramnarayanan K, et al: Genomic loss of microRNA-101 leads to overexpression of histone methyltransferase EZH2 in cancer. Science 322: 1695-1699, 2008.

15. Elzein S and Goodyer CG: Regulation of human growth hormone receptor expression by microRNAs. Mol Endocrinol 28: 1448-1459, 2014.

16. Bijnsdorp IV, Hodzic J, Lagerweij T, Westerman B, Krijgsman O, Broeke J, Verweij F, Nilsson RJ, Rozendaal L, van Beusechem VW, et al: miR-129-3p controls centrosome number in metastatic prostate cancer cells by repressing CP110. Oncotarget 7: 16676-16687, 2016.

17. Huang S, Liao Q, Li L and Xin D: PTTG1 inhibits SMAD3 in prostate cancer cells to promote their proliferation. Tumour Biol 35: 6265-6270, 2014

18. Majumder S, Bhowal A, Basu S, Mukherjee P, Chatterji U and Sengupta S: Deregulated E2F5/p38/SMAD3 circuitry reinforces the pro-tumorigenic switch of TGF $\beta$ signaling in prostate cancer. J Cell Physiol 231: 2482-2492, 2016.

19. Yao B, Zhao J, Li Y, Li H, Hu Z, Pan P, Zhang Y, Du E, Liu R and Xu Y: Elf5 inhibits TGF- $\beta$-driven epithelial-mesenchymal transition in prostate cancer by repressing SMAD3 activation. Prostate 75: 872-882, 2015
20. Lu S, Lee J, Revelo M, Wang X, Lu S and Dong Z: Smad3 is overexpressed in advanced human prostate cancer and necessary for progressive growth of prostate cancer cells in nude mice. Clin Cancer Res 13: 5692-5702, 2007.

21. Virgo KS, Rumble RB and Singer EA: Second-line hormonal therapy for men with chemotherapy-naïve castration-resistant prostate cancer: American Society of Clinical Oncology Provisional Clinical Opinion Summary. J Oncol Pract 13: 459-461, 2017.

22. Teixeira AL, Gomes M, Nogueira A, Azevedo AS, Assis J, Dias F, Santos JI, Lobo F, Morais A, Maurício J, et al: Improvement of a predictive model of castration-resistant prostate cancer: Functional genetic variants in TGF $\beta 1$ signaling pathway modulation. PLoS One 8: e72419-e72419, 2013.

23. Song K, Wang H, Krebs TL, Wang B, Kelley TJ and Danielpour D: DHT selectively reverses Smad3-mediated/TGF-beta-induced responses through transcriptional down-regulation of Smad3 in prostate epithelial cells. Mol Endocrinol 24: 2019-2029, 2010.

24. Ma L, Chen X, Li C, Cheng R, Gao Z, Meng X, Sun C, Liang C and Liu Y: miR-129-5p and -3p co-target WWP1 to suppress gastric cancer proliferation and migration. J Cell Biochem: Nov 11, 2018 (Epub ahead of print). doi: 10.1002/jcb.28027.

25. Fang D-Z, Wang Y-P, Liu J, Hui XB, Wang XD, Chen X and Liu D: MicroRNA-129-3p suppresses tumor growth by targeting E2F5 in glioblastoma. Eur Rev Med Pharmacol Sci 22: 1044-1050, 2018

This work is licensed under a Creative Common Attribution-NonCommercial-NoDerivatives 4.0 International (CC BY-NC-ND 4.0) License. 